\title{
Protocol
}

\section{Measuring Angiogenesis and Hemodynamics in Mice}

\author{
Rakesh K. Jain, Lance L. Munn, and Dai Fukumura
}

This protocol outlines methods to measure vascular parameters, including angiogenesis (e.g., vascular density, length, diameter) and hemodynamics (e.g., erythrocyte velocity), in tumors and normal vascular networks in mice. Fluorescein-isothiocyanate (FITC)-dextran is injected into the tail vein of mice to visualize microvessels within $150 \mu \mathrm{m}$ (using single-photon microscopy) or $\sim 600 \mu \mathrm{m}$ (using multiphoton laser-scanning microscopy [MPLSM]) of a tumor/window interface. Randomly selected areas (three to six locations/tumor or animal) are investigated using long-working-distance objectives with appropriate magnification. During each observation period, FITC-fluorescence images are recorded for $60 \mathrm{sec}$, and the videotapes are analyzed off-line for single-photon microscopy; or a threedimensional (3D) image stack of the vessel network is generated, and vessel properties are measured for MPLSM. If desired, red blood cell (RBC) flux can be measured on a vessel-by-vessel basis using fluorescent tracer RBCs.

It is essential that you consult the appropriate Material Safety Data Sheets and your institution's Environmental Health and Safety Office for proper handling of equipment and hazardous materials used in this protocol.

\section{Reagents}

Anesthetic, isofluorane $1 \%-3 \%$ inhalant (up to $5 \%$ for induction) or ketamine ( $80-100 \mathrm{mg} / \mathrm{kg}$ body weight $[\mathrm{BW}]) /$ xylazine $(5-10 \mathrm{mg} / \mathrm{kg} \mathrm{BW})$

FITC-dextran (MW $\left.2 \times 10^{6} ; 10 \mathrm{mg} / \mathrm{mL}\right)$

Lipophilic fluorescent dye for labeling RBCs (optional; see Step 10 and Discussion)

Equipment

Four-slit apparatus (Microflow System, model 208C, video photometer version, IPM or equivalent) Heating pad or similar device

Image-shearing device (digital video image shearing monitor, model 908, IPM or equivalent)

Imaging setup:

- Conventional single-photon microscope

The standard microscopy workstation consists of an upright or inverted microscope equipped with transillumination and fluorescence epi-illumination, a flashlamp excitation device, a set of fluorescence filters, a motor-controlled filter wheel, a charge-coupled device (CCD) camera, a video monitor, a video recorder, and a frame-grabber board for image digitization (Fig. 1A). Alternatively, spinning-disk confocal microscopes or laser-scanning confocal microscopes can be used. Advanced techniques require additional equipment

Adapted from Live Cell Imaging, 2nd edition (ed. Goldman et al.). CSHL Press, Cold Spring Harbor, NY, USA, 2010.

(C) 2013 Cold Spring Harbor Laboratory Press

Cite this article as Cold Spring Harb Protoc; 2013; doi:10.1101/pdb.prot073916 
A Conventional Epifluorescence Intravital Microscopy

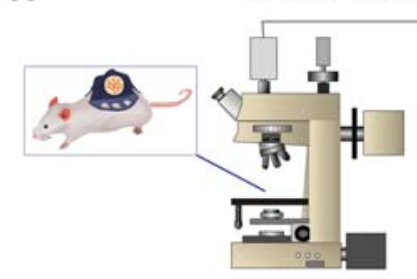

Upright microscope

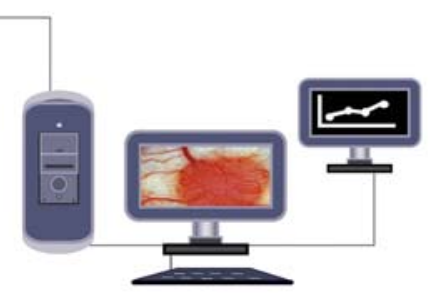

Digital image acquisition \& analysis station

B

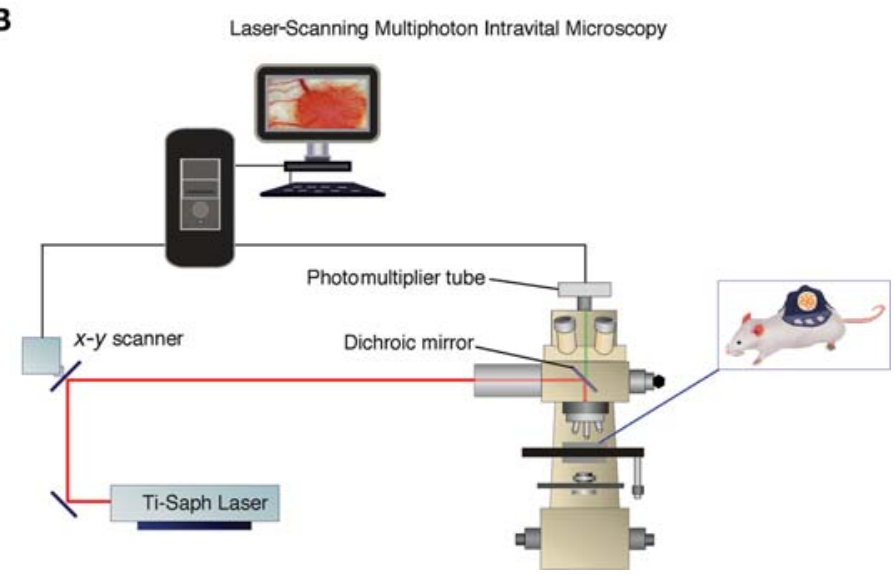

FIGURE 1. Intravital microscopy workstations. Mouse tumor models are observed using $(A)$ conventional intravital microscopy or $(B)$ MPLSM. With appropriate tracer molecules and/or engineered vectors/cells and computer-assisted image analysis, one can monitor tumor size, vessel density, vessel diameter, RBC velocity, leukocyte endothelial interaction, vascular permeability, tissue $\mathrm{pO}_{2}, \mathrm{pH}$, gene promoter activity, enzyme activity, and delivery of drugs, including genes. (B: Adapted, with permission, from Brown et al. 2001.)

such as a motorized $x-y$ stage with $\pm 1.0-\mu m$ lateral resolution, an intensified CCD camera, a photomultiplier tube, and a dual-trace digital oscilloscope (Berk et al. 1997; Fukumura et al. 1997a; Helmlinger et al. 1997; Jain et al. 2001, 2002).

\section{- MPLSM}

The MPLSM consists of a mode-locked Ti:sapphire laser and a laser scan head purchased either as part of a multiphoton system or as a confocal system with further modifications for good infrared transmission. The laser beam first passes through a Pockels cell, which allows rapid $(\sim 1-\mu \mathrm{sec})$ modulation of laser intensity and then is directed by the scan head into the side-entry or top-entry port of an upright epifluorescence microscope. Nondescanned photomultiplier tubes are used for imaging through significant depths of scattering tissue and should be introduced into the beam path via a dichroic beam splitter located in the beam path between the scan head and the objective lens (Fig. 1B) (Denk et al. 1990; Brown et al. 2001).

Perform imaging procedures with the animal under appropriate anesthesia and with full approval by the Institutional Animal Care and Use Committee. During the procedure, maintain the animal's core body temperature at $36^{\circ} \mathrm{C}-37^{\circ} \mathrm{C}$ using a heating pad or similar device.

\section{Injection of Tracer}

1. Inject $100 \mu \mathrm{L}$ of FITC-dextran (MW $2 \times 10^{6}, 10 \mathrm{mg} / \mathrm{mL}$ ) into the tail vein of the mouse.

For the single-photon microscopy procedure, proceed to Step 2. For the MPLSM procedure, proceed to Step 6. 
R.K. Jain et al.

Single-Photon Microscopy Procedure

Figure 2 illustrates angiogenesis as observed with single-photon microscopy.

2. Measure the vessel diameter (D) using an image-shearing device (Kaufman and Intaglietta 1985).

3. Measure the transverse RBC velocity (i.e., the RBC velocity in the plane of the image [VTRBC]), by temporal correlation velocimetry using a four-slit apparatus connected to a personal computer (Intaglietta and Tompkins 1973).

4. Calculate the mean transverse blood flow rate of individual vessels $\left(Q_{T}\right)$ using $D$ and the mean $V_{\text {TRBC }}\left(V_{\text {Tmean }}\right) . Q_{T}=\pi / 4 \times V_{\text {Tmean }} \times D^{2}$, where $V_{\text {Tmean }}=V_{\text {TRBC }} / a(a=1.3$ for blood vessels $<10$ $\mu \mathrm{m} ; a=1.6$ for blood vessels $>15 \mu \mathrm{m}$; and, by linear extrapolation, $1.3<a<1.6$ for blood vessels between $10 \mu \mathrm{m}$ and $15 \mu \mathrm{m}$ ) (Lipowsky and Zweifach 1978).

5. Use an image-processing system to analyze the two-dimensional functional vessel density, which is a measure of angiogenesis that is defined as the total length of vessels per unit area of the image $\left(\mathrm{cm} / \mathrm{cm}^{2}\right)$, and the two-dimensional branching index, which is defined as the mean length of unbranched segments $(\mu \mathrm{m})$ in the plane of the image (Fukumura et al. 1997a,b; Jain et al. 1997).

MPLSM Procedure

Figure 3 illustrates tumor microcirculation imaged with MPLSM.

6. Measure the vessel diameters in micrometers $(D)$ from the image stack using image-analysis software (Abdul-Karim et al. 2003).

7. Measure the transverse RBC velocity $\left(V_{\text {TRBC }}\right)$ by the line-scan technique (Brown et al. 2001). (Because the majority of laser-scanning microscopes [LSMs], including both confocal and multiphoton LSMs, only scan in a single direction, this technique produces the RBC velocity tangential to the direction of the line scan.) Subsequently, calculate the absolute RBC velocity $\left(V_{\mathrm{RBC}}\right)$ by determining the angle $\theta$ between the line scan and the axis of the vessel using the 3D image stack. The true RBC velocity is then $V_{\mathrm{RBC}}=V_{\mathrm{TRBC}} / \cos \theta$.

8. Calculate the mean absolute blood flow rate of individual vessels $(Q)$ using $D$ and the mean $V_{\text {RBC }}$ $\left(\mathrm{V}_{\text {mean }}\right) . Q=\pi / 4 \times V_{\text {mean }} \times D^{2}$, where $V_{\text {mean }}=V_{\mathrm{RBC}} / a(a=1.3$ for blood vessels $<10 \mu \mathrm{m} ; a=1.6$ for blood vessels $>15 \mu \mathrm{m}$; and, by linear extrapolation, $1.3<a<1.6$ for blood vessels between 10 $\mu \mathrm{m}$ and $15 \mu \mathrm{m}$ ) (Lipowsky and Zweifach 1978).

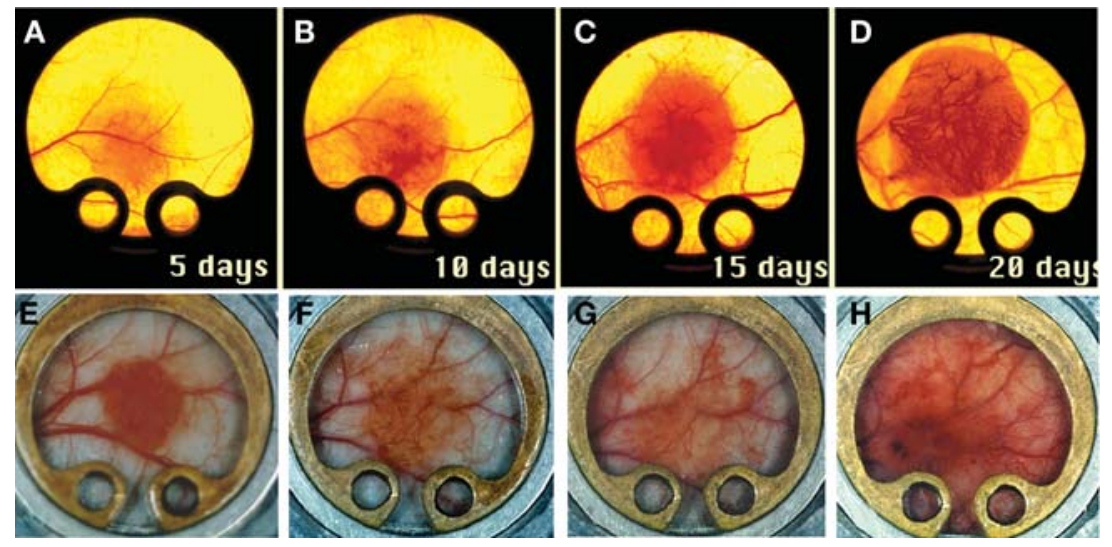

FIGURE 2. Angiogenesis, tumor growth, and regression in the dorsal skin chamber. $(A-D)$ Angiogenesis and tumor growth in a human colon carcinoma. At day 5 after tumor cell implantation, enlargement of host vessels is observed and by day 10 , occasional hemorrhage and sprout formation occurs. At day 15, tumor growth and further angiogenesis become apparent. By day 20, the tumor is fully vascularized. $(E-H)$ Tumor growth and regression in a Shionogi mouse mammary carcinoma. Shown are $(E) 12 \mathrm{~d}$ tumor before orchiectomy as well as $(F) 3 \mathrm{~d}$ and $(G) 9 \mathrm{~d}$ after orchiectomy, when the tumor vessels regress and the tumor shrinks. A second wave of angiogenesis is evident in $H$. ( $A-D$ : Adapted from Leunig et al. 1992; $E-H$ : adapted, with permission, from Jain et al. 1998.) 


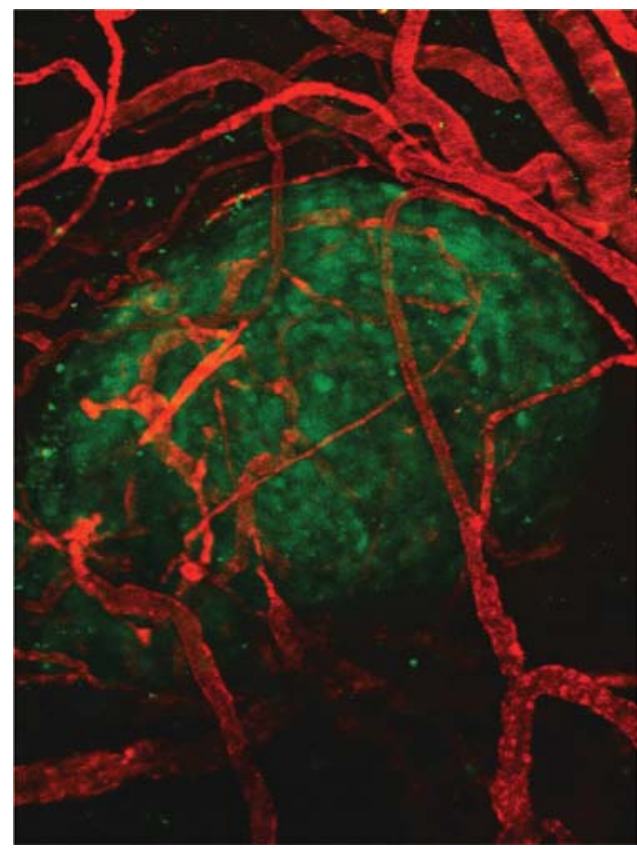

FIGURE 3. Tumor microcirculation imaged with MPLSM. A spontaneous metastasis of a U87 human glioblastoma growing in the cranial window of a SCID mouse. Vessels are highlighted with an intravenous injection of $0.2 \mathrm{~mL}$ of $10-\mathrm{mg} / \mathrm{mL}$ of $2 \times 10^{6}$-MW FITC-dextran. The image shown is a maximum intensity projection of 74 optical sections spaced $2 \mu \mathrm{m}$ apart. Image is $500 \mu \mathrm{m}$ across. (Image courtesy of E. di Tomaso.)

9. Use an image-processing system to analyze from the $3 \mathrm{D}$ image stack the $3 \mathrm{D}$ functional vessel density, which is a measure of angiogenesis that is defined as the total length of vessels per unit volume $\left(\mathrm{cm} / \mathrm{cm}^{3}\right)$, and the branching index, which is defined as the mean length of unbranched segments $(\mu \mathrm{m})$ (Abdul-Karim et al. 2003).

10. If desired, measure RBC flux on a vessel-by-vessel basis using fluorescent tracer RBCs.

See Discussion.

Common Analysis

11. If desired, measure the fractal dimensions of vessels as described elsewhere (Gazit et al. 1995; Baish and Jain 2000).

We have developed two MPLSM-based methods for blood flow analysis in tumors and normal vascular networks (Kamoun et al. 2008). The first method allows direct analysis of 3D flow velocity through a single vessel by measuring RBC resident time rather than displacement: resident time line scanning (rtLS). The second method is a full-field method that permits analysis of most vessels within a field of view by using a relativistic approach relating flow velocity and laser-scanning velocity: relativistic full field flow. To perform hemodynamic analysis of vessels, label RBCs ex vivo with a lipophilic fluorescent dye with a far-red emission fluorescence spectrum that allows deep penetration and multichannel imaging. When injected intravenously into the mouse blood, the fluorescent RBC fraction is stable for several days with a half-life of $\sim 10 \mathrm{~d}$. Then perform rtLS by scanning along a line that intersects with the vessel direction (Kamoun et al. 2008). Repetitive scanning along this line generates an image in which the shape of the RBCs is distorted (compressed or elongated) based on its displacement relative to the line scan frequency. The RBC distortion length along the time axis represents the number of times the laser scans the RBC, which is equivalent to the RBC resident time. A lattice Boltzmann-based mathematical simulation can be used to validate the analytical solutions. 
The work described here was supported by grants from the National Institutes of Health, the National Science Foundation, the American Cancer Society, the United States Army, the National Foundation for Cancer Research, and the Whitaker Foundation.

\section{REFERENCES}

Abdul-Karim A, Al-Kofahi K, Brown E, Jain RK, Roysam B. 2003. Automated tracing and change analysis of angiogenic vasculature from in vivo multiphoton image time series. Microvasc Res 66: 113-125.

Baish JW, Jain RK. 2000. Fractals and cancer. Cancer Res 60: 3683-3688.

Berk DA, Yuan F, Leunig M, Jain RK. 1997. Direct in vivo measurement of targeted binding in a human tumor xenograft. Proc Natl Acad Sci 94: 1785-1790.

Brown EB, Campbell RB, Tsuzuki Y, Xu L, Carmeliet P, Fukumura D, Jain RK. 2001. In vivo measurement of gene expression, angiogenesis, and physiological function in tumors using multiphoton laser scanning microscopy. Nat Med 7: 864-868.

Denk W, Strickler JH, Webb WW. 1990. Two-photon laser scanning fluorescence microscopy. Science 248: 73-76.

Fukumura D, Yuan F, Endo M, Jain RK. 1997a. Role of nitric oxide in tumor microcirculation: Blood flow, vascular permeability, and leukocyte-endothelial interactions. Am J Pathol 150: 713-725.

Fukumura D, Yuan F, Monsky WL, Chen Y, Jain RK. 1997b. Effect of host microenvironment on the microcirculation of human colon7 adenocarcinoma. Am J Pathol 151: 679-688.

to Gazit Y, Berk DA, Leunig M, Baxter LT, Jain RK. 1995. Scale-invariant behavior and vascular network formation in normal and tumor tissue. Phys Rev Lett 75: 2428-2431.

Helmlinger G, Yuan F, Dellian M, Jain RK. 1997. Interstitial $\mathrm{pH}$ and $\mathrm{pO}_{2}$ gradients in solid tumors in vivo: High-resolution measurements reveal a lack of correlation. Nat Med 3: 177-182.
Intaglietta M, Tompkins WR. 1973. Microvascular measurements by video image shearing and splitting. Microvasc Res 5: 309-12.

Jain RK, Schlenger K, Hockel M, Yuan F. 1997. Quantitative angiogenesis assays: Progress and problems. Nat Med 3: 1203-1208.

Jain RK, Safabakhsh N, Sckell A, Chen Y, Jiang P, Benjamin L, Yuan F, Keshet E. 1998. Endothelial cell death, angiogenesis, and microvascular function after castration in an androgen-dependent tumor: Role of vascular endothelial growth factor. Proc Natl Acad Sci 95: 10820-10825.

Jain RK, Munn LL, Fukumura D. 2001. Transparent window models and intravital microscopy. In Tumor models in cancer research (ed. BA Teicher), pp. 647-671. Humana, Totowa, NJ.

Jain RK, Munn LL, Fukumura D. 2002. Dissecting tumor pathophysiology using intravital microscopy. Nat Rev Cancer 2: 266-276.

Kamoun W, Jain R, Munn L. 2008. Simultaenous measurements of tumor vessel topology, perfusion and vascular permeability. In AACR Meeting Abstracts, p. 457. San Diego, CA.

Kaufman AG, Intaglietta M. 1985. Automated diameter measurement of vasomotion by cross-correlation. Int J Microcirc Clin Exp 4: 45-53.

Leunig M, Yuan F, Menger MD, Boucher Y, Goetz AE, Messmer K, Jain RK. 1992. Angiogenesis, microvascular architecture, microhemodynamics, and interstitial fluid pressure during early growth of human adenocarcinoma LS174T in SCID mice. Cancer Res 52: 6553-6560.

Lipowsky HH, Zweifach BW. 1978. Applications of the "two-slit" photometric technique to the measurement of microvascular volumetric flow rates. Microvasc Res 15: 93-101. 


\section{Measuring Angiogenesis and Hemodynamics in Mice}

Rakesh K. Jain, Lance L. Munn and Dai Fukumura

Cold Spring Harb Protoc; doi: 10.1101/pdb.prot073916

\begin{tabular}{cc}
$\begin{array}{c}\text { Email Alerting } \\
\text { Service }\end{array}$ & Receive free email alerts when new articles cite this article - click here. \\
\hline $\begin{array}{c}\text { Subject } \\
\text { Categories }\end{array}$ & $\begin{array}{c}\text { Browse articles on similar topics from Cold Spring Harbor Protocols. } \\
\text { Fluorescence (517 articles) } \\
\text { Fluorescence, general (341 articles) } \\
\text { Image Analysis (124 articles) } \\
\text { In Vivo Imaging (334 articles) } \\
\text { In Vivo Imaging, general (168 articles) } \\
\text { Mouse (437 articles) } \\
\text { Multi-Photon Microscopy (103 articles) } \\
\text { Video Imaging / Time Lapse Imaging (171 articles) }\end{array}$ \\
\hline
\end{tabular}

